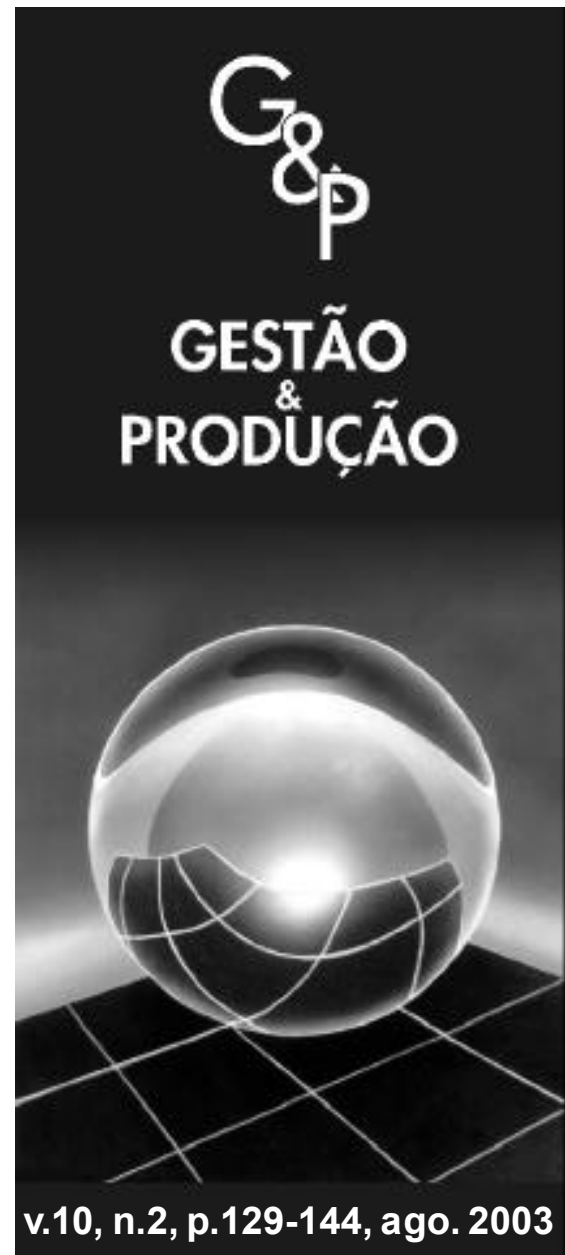

\title{
ESTRATÉGIAS COMPETITIVAS E COMPETÊNCIAS ESSENCIAIS: PERSPECTIVAS PARA A INTERNACIONALIZAÇÃO DA INDÚSTRIA NO BRASIL
}

\author{
Afonso C. C. Fleury \\ Departamento de Engenharia de Produção \\ da Escola Politécnica da USP, av. Almeida Padro, 531, \\ CEP 05508, São Paulo, e-mail: acfleury@usp.br
}

Maria Tereza Leme Fleury

Faculdade de Economia e Administração da Universidade de São Paulo, Av. Professor Luciano Gualberto, 908, CEP 05508, São Paulo, e-mail: mtfleury@usp.br

Recebido em 7/8/2002

Aceito em 29/4/2003

\section{Resumo}

Uma das principais características da nova economia é a transição da eficiência individual para a eficiência coletiva. A competitividade é, e será cada vez mais, relacionada ao desempenho de redes interorganizacionais e não de empresas isoladas. Ao mesmo tempo, a formação dessas redes tem forte dimensão locacional, associada ao movimento de internacionalização das operações das grandes corporações transnacionais. Do ponto de vista de economias emergentes como a brasileira, importantes mudanças estão tendo lugar, como conseqüencia do posicionamento de suas empresas nessas novas redes interorganizacionais internacionais. Este é o foco deste estudo. Um modelo analítico foi desenvolvido para a avaliação de quais setores industriais apresentam potencial para se tornarem competitivos internacionalmente, por demonstrarem possuir as competências organizacionais necessárias. $O$ referencial conceitual foi construido a partir da idéia de que a participação numa rede interorganizacional depende das competências organizacionais desenvolvidas pela empresa e que essa participação vai implicar mudanças na definição de sua estratégia competitiva. A aplicação do modelo foi operacionalizada em um amplo survey da indústria no país. Os resultados permitem realizar uma primeira identificação do posicionamento das empresas em redes internacionais assim como avaliar a competitividade em seus diferentes setores industriais.

Palavras-chave: estratégias competitivas, gestão de competências, manufatura internacional, cadeias de fornecimento, redes interorganizacionais, indústria brasileira. 


\section{Apresentação}

$\mathrm{O}$ processo de globalização dos negócios está acelerando o ritmo de mudanças em termos de como a produção de bens e serviços está sendo projetada e implementada. Após a concepção universalista e hegemônica de fábricas tayloristasfordistas de grande escala, altamente integradas, observa-se a emergência de um complexo sistema de novos conceitos e fórmulas para a organização dos negócios em geral e para a função Produção ou Operações em particular. Empresas globais estão não só se reestruturando segundo uma perspectiva de integração internacional (Bartlett \& Ghoshal, 1989; Prahalad \& Lieberthal, 1998; entre outros), mas também estão redefinindo suas relações com as empresas em outros países. Temas como Global Operations Management (Flaherty, 1996), International Manufacturing (Shi \& Gregory, 1998) e International Supply Chain Management (Akkermans et al., 1999; Motwani et al., 1999) surgem como novas áreas de pesquisa.

$\mathrm{O}$ ponto que se pretende levantar neste artigo diz respeito ao posicionamento das empresas e do país nesse novo contexto, caracterizado por redes interorganizacionais internacionais. Para isso, partimos da idéia de que o mais importante fator na estruturação dessas redes são as competências organizacionais: a participação e a posição de cada empresa é função de suas competências. A posição na rede e a forma pela qual as competências são administradas vão, por sua vez, influenciar as estratégias competitivas.

Partimos das seguintes considerações:

- no intenso e profundo processo de reestruturação das empresas e de seus negócios, a competitividade exige eficiência coletiva; empresas terão de focar suas competências essenciais (core competences) e procurar parcerias para complementar recursos e realizar seus objetivos;

- diferentes tipos de redes interorganizacionais estão sendo observadas; esses arranjos são resultados de processos históricos e decisões empresariais atuais;
- a participação de uma empresa em uma rede interorganizacional requer mudanças significativas no modo pelo qual a empresa toma decisões e opera.

Para responder à questão principal: "Em um nível agregado (por exemplo, regional ou nacional), como podemos analisar a dinâmica de redes interorganizacionais internacionais e suas conseqüências, utilizando os conceitos de Gestão de Produção e Operações?", tivemos, primeiro, de trabalhar em dois outros níveis:

- Para uma empresa, o que acontece quando ela se torna membro de um arranjo interorganizacional? Quais as consequiências para a formulação de estratégias e para o desenvolvimento de competências?

- Numa rede interorganizacional, como se pode compreender as questões de alinhamento estratégico e de formação coletiva de competências?

Visando responder a essas perguntas, elaboramos, de início, um modelo relacionando estratégia e competências no plano de empresa individual. Em seguida, fizemos um estudo das novas formas de arranjos interorganizacionais com o objetivo de caracterizar a lógica da formulação de estratégias e da formação de competências, nas situações em que a interdependência organizacional é característica competitiva. Esse referencial conceitual serviu para a preparação de um survey sobre a indústria brasileira: enviamos cerca de 1.600 questionários e obtivemos 470 respostas em condições de serem processadas.

A aplicação dessa metodologia resultou em visão panorâmica da articulação da indústria local no contexto internacional e no delineamento de uma nova arquitetura da indústria globalizada com foco no Brasil. A partir daí foram tratadas as consequiências do processo de internacionalização, o modo adotado por empresas transnacionais e suas subsidiárias para moldar suas redes, o novo espaço e escopo para a formulação de estratégias no caso das empresas brasileiras e o novo perfil das competências requeridas. 


\section{O que torna uma empresa competitiva?}

Os debates sobre os fatores que determinam a competitividade das empresas têm sido enriquecidos nos últimos anos com novas abordagens.

A abordagem clássica é a "análise da indústria" ou do "posicionamento estratégico", que tem em Michael Porter seu maior protagonista. Esta abordagem prioriza a análise dos mercados e da competição e o entendimento da posição relativa de cada empresa em sua indústria ou segmento produtivo como elementos primordiais no processo de formulação da estratégia (Porter, 1980, 1996). Os principais focos de análise são produtos, consumidores e competidores, e a estratégia da empresa deve ser resultante da identificação de tendências e de oportunidades. Nesse sentido, é considerada uma abordagem "de fora para dentro".

Os instrumentos básicos para o posicionamento estratégico incluem uma estrutura analítica relativamente simples mas extremamente poderosa baseada em "cinco forças" e uma matriz dois por dois, em função da qual se caracterizam as estratégias competitivas genéricas. Essa abordagem, proposta por Michael Porter em 1980, em Vantagem Competitiva, foi posteriormente aperfeiçoada. O próprio Porter, em 1985, já ampliava seu foco com o conceito de cadeia de valor e sistema de valor, reconhecendo "as atividades da empresa" como base da vantagem competitiva: "Os drivers para a redução de custos ou para a diferenciação serão identificados a partir das atividades e das ligações entre elas" (Proença, 1999). Como coloca o próprio Porter, "as escolhas de posicionamento determinam não somente quais atividades a empresa desempenhará e como essas atividades serão configuradas, mas também como essas atividades estarão relacionadas entre si" (Porter, 1996). Em outras palavras, ao incorporar questões ligadas à organização interna da empresa, a abordagem do posicionamento competitivo mantém e reforça a perspectiva "de fora para dentro".

Com o tempo, as críticas à análise do posicionamento estratégico vêm se avolumando. A maior delas diz respeito a sua natureza estritamente estática. Para Proença (1999), os frameworks não dão resposta às questões mais cruciais para o tomador de decisão: por que certas firmas foram capazes de construir posições de vantagem e sustentá-las ou falharam na tentativa? O autor comenta que, "na visão jocosa dos profissionais da área, trata-se de um excelente método para saber por que os outros estão, neste momento, se dando bem e você não". Também no plano acadêmico as críticas são severas. Por exemplo, D’Aveni (1995), assim como Day \& Reibstein (1998), da Wharton Business School, argumentam que "(...) estratégia é crescentemente dinâmica e complexa”. Usando as metáforas da imitação e da erosão das vantagens competitivas no tempo, os autores advertem que "não é mais possível esperar pelo competidor para agir ou reagir".

Uma abordagem alternativa está sendo construída a partir da "visão da empresa baseada em recursos" (Resources Based View of the Firm). Essa abordagem procura ampliar e refinar o quadro de referência dos tomadores de decisão. Considera que toda empresa possui um portfolio de recursos: físicos, financeiros, intangíveis (marca, imagem), organizacionais (cultura organizacional, sistemas administrativos) e recursos humanos. É a partir desse portfolio que a empresa pode criar vantagens competitivas. Para os defensores dessa abordagem (Prahalad \& Hamel, 1990; Krogh \& Ross, 1995), a definição das estratégias competitivas deve partir de uma perfeita compreensão das possibilidades estratégicas passíveis de serem operacionalizadas e sustentadas por tais recursos. Isto caracteriza essa abordagem como primordialmente "de dentro para fora".

"A VBR postula que as empresas com pessoas, estruturas e sistemas superiores são mais lucrativas, não porque invistam em barreiras de entrada para 
outras empresas ou porque ofereçam produtos diferenciados, mas sim porque elas se apropriam das rendas de recursos específicos da firma. (...) Como já afirmava Teece, em 1982, a diversificação é menos uma resposta às imperfeições estruturais dos mercados e mais um mecanismo organizacional para capturar rendimentos que são tornados viáveis pelos ativos específicos da empresa" (Proença, 1999). Em outras palavras, diferenciação é uma visão e uma decisão de dentro para fora mais do que uma informação de fora para dentro; são os recursos da empresa, consubstanciados em competências e capacitações que criam e exploram lucrativamente um potencial de diferenciação latente nos mercados.

Outra premissa básica da VBR é de que as firmas diferem de forma fundamental em seus modos de operar porque cada uma delas possuirá um agrupamento singular de recursos - seus ativos, competências e capacitações específicas. Dosi \& Coriat (2002) observam que “(...) firmas têm formas diferentes de fazer as coisas: se elas são heterogêneas até no modo de realizar tarefas similares, o que não dizer das distinções de grande escala que separam as empresas químicas das automobilísticas, das empresas varejistas, dos hospitais".

Tidd et al. (1998) classificam a abordagem da análise da indústria como racionalista e a Visão Baseada em Recursos como incrementalista: a primeira seria "fortemente influenciada pela experiência militar" e inadequada para ambientes complexos e de mudanças rápidas. Eles recomendam a adoção da segunda, "a qual deve ser encarada como uma forma de aprendizagem e experiência corporativa em termos de combinar maior eficiência com complexidade e mudanças". Dosi \& Coriat (2002) assumem que "o que está ocorrendo é o tradicional movimento pendular: o foco sobre as competências e os recursos segue o período no qual as pesquisas sobre estratégia empresarial foi reenergizada por conceitos econômicos retirados da Economia Industrial e que focalizava primordialmente a relação da empresa com o seu ambiente competitivo: esta [nova] perspectiva sobre organizações e aprendizagem organizacional, claramente, retira o foco da análise tanto do posicionamento competitivo do produto quanto da 'estratégia esperta' e o recoloca sobre (...) estratégias de aprimoramento das competências".

Como seria esperado, os defensores do Posicionamento Estratégico reagem: "Em empresas competitivas pode ser enganoso explicar o sucesso a partir da identificação de seus específicos pontos fortes, competências essenciais ou recursos críticos" (Porter, 1996). Não obstante, o mesmo autor, ao criticar a busca desenfreada por crescimento, pede serenidade nessa decisão e dá um conselho que parece derivar da VBR: "Uma alternativa é buscar extensões da estratégia que alavanquem o sistema de atividades existentes de maneira a criar serviços ou especificações que os rivais considerem ser impossível combater em bases individiais" (Porter, 1996).

Em síntese, a nosso ver, está havendo convergência entre as abordagens, não obstante uma distinção entre pressupostos (de fora para dentro versus de dentro para fora) ainda marque o campo de disputa entre autores. ${ }^{1}$

Entre as duas, optamos pela abordagem a partir da Visão Baseada em Recursos. A maior crítica a essa abordagem está na dificuldade para a criação do framework analítico (Gilgeous \& Parveen, 2001). Para enfrentar esse problema, criamos uma abordagem que procura combinar estratégia competitiva, aprendizagem e formação de competências num modelo dinâmico, como o apresentado na Figura 1.

1. Parece-nos relevante observar que nessa disputa estão envolvidos grandes interesses econômicos; não é apenas uma discussão acadêmica. Para outros detalhes veja Cole (1989) e Miyake (1995). 


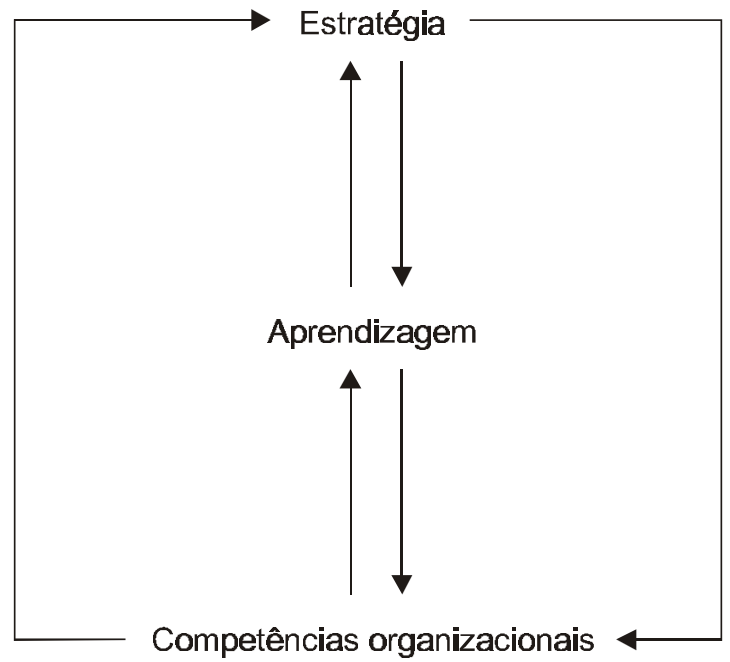

Figura 1 - $O$ ciclo de estratégia: competência.

A formulação da estratégia competitiva deve buscar potencializar a competência na qual a empresa é mais forte. A constante evolução das competências da empresa permite o sistemático refinamento e reformulação da estratégia competitiva e, a partir desta, são identificadas novas orientações para a formação de competências. A manutenção da relação dinâmica entre estratégia e competência é o principal objetivo dos processos de aprendizagem.

\subsection{Construindo uma tipologia de competências organizacionais}

O termo competência essencial (core competence) ganhou importância no cenário administrativo a partir do artigo "The core competence of the corporation", de Prahalad \& Hamel, em 1990. De acordo com os autores, competências essenciais são recursos intangíveis que (a) em relação aos concorrentes são difíceis de ser imitados, (b) em relação a mercados e clientes são os recursos essenciais para que a empresa possa prover produtos/serviços diferenciados e (c) em relação ao processo de mudança e evolução da própria empresa são o fator fundamental da maior flexibilidade que permite a exploração de diferentes mercados. As competências essenciais não estão estritamente relacionadas à tecnologia: elas podem estar localizadas em qualquer função administrativa. Além disso, para desenvolver competência essencial a longo prazo, a companhia necessita de um processo sistemático de aprendizagem e inovação organizacional.

Procurando avançar nessa discussão e construir uma tipologia que dê sustentação ao modelo de estratégia e formação de competências, remetemos inicialmente ao trabalho de Woodward (1965). Seguindo a abordagem utilizada por essa autora em seu estudo clássico, Industrial Organisation: theory and practice, consideramos que toda empresa possui, em diferentes proporções, competências relacionadas a três diferentes funções: Operações (Produção e Logística), Desenvolvimento de Produto e Comercialização (Vendas \& Marketing).

Em sua extensa pesquisa em empresas britânicas, Woodward constatou que, dependendo do tipo de produto/mercado, uma das funções vai ser mais importante e "ter mais poder" do que as outras, na medida em que exercerá um papel de coordenação geral entre as funções. 
Para a construção de nossa abordagem isso significa que, para a realização da estratégia da empresa, as competências acumuladas nessa função crítica constituem "a competência essencial da empresa"; ela é a mais importante para a realização da estratégia competitiva da empresa. As outras duas funções são funções de apoio. O mesmo dizemos para essas competências.

Não queremos com isso afirmar que a empresa deve se concentrar em apenas uma das três competências e abandonar as outras duas. $\mathrm{O}$ ponto que queremos destacar é que não é interessante para qualquer empresa assumir que é, ou deveria ser, igualmente competente em todas as funções. Para o desempenho competitivo da empresa, uma das competências vai ser mais relevante que as outras. A competitividade será maximizada quando houver alinhamento correto entre competência essencial e estratégia competitiva. As demais competências devem sempre ser desenvolvidas tendo em vista reforçar a competência essencial. Tudo é questão de priorização e equilíbrio entre as três competências. Este ponto será mais detalhado a seguir.

\subsection{Estratégias competitivas e competências organizacionais}

Consideraremos que qualquer estratégia competitiva, independentemente de suas características mais específicas, pode ser classificada em uma de três categorias: Excelência Operacional, Inovação em Produto e Relação com o Cliente. Essa tipologia, fortemente baseada em Treacy \& Wiersema (1995) e em Porter (1996), é elaborada a seguir.

\subsubsection{Excelência Operacional}

A estratégia de Excelência Operacional é aplicada pelas empresas que competem em mercados nos quais a relação qualidade/preço é a maior determinante da competitividade de produtos ou serviços.

É nesses casos que encontramos as "estratégias baseadas em operações”, como descritas por
Hayes \& Upton (1998): "Eficiência operacional superior fortalece a posição competitiva da empresa e, quando baseada nas capacidades dos seus recursos humanos e nos seus processos operacionais, dificulta a imitação pelos concorrentes. Por essa razão, pode prover a base para uma vantagem competitiva sustentável, mesmo que a companhia adote a mesma posição competitiva de uma ou mais concorrentes".

Exemplo típico de Excelência Operacional é o das empresas automobilísticas, com destaque para a Ford no passado e a Toyota atualmente. No mercado de computadores, Compaq e Dell são os maiores exemplos. No setor de serviços, McDonalds e WalMart, entre outras, são casos de renome internacional.

A estratégia de Excelência Operacional implica desenvolver e colocar no mercado produtos/ serviços que otimizem a relação qualidade/preço. A lucratividade da empresa é função direta da margem por produto e da escala de produção.

A função crítica para o sucesso da companhia é Operações, incluindo todo o ciclo logístico: suprimento, produção e distribuição. É nessa função que reside a competência essencial, aquela que deve ser priorizada para que a empresa seja competitiva. Na indústria, o modelo da lean production tem sido considerado como o "ideal" a ser alcançado.

Como mencionado anteriormente, a construção de competências nas duas outras áreas, Desenvolvimento de Produto/Serviços e Vendas/ Marketing (S\&M), deve visar ao aumento de competitividade da empresa, por intermédio de Operações.

$\mathrm{Na}$ área de desenvolvimento, a empresa busca, prioritariamente, inovações incrementais em produtos e serviços. Do ponto de vista da competitividade da empresa, mudanças em processos podem ter impacto tão grande ou maior que inovações em produto/serviço. Exemplo interessante é dado pelo recente desenvolvimento, pela Honda, de um novo tipo único de plataforma que permite a montagem de veículos de diferentes modelos e tamanhos, evitando a necessidade de um tipo específico de plataforma para cada tamanho de veículo. Isso tem profundo impacto 
nos custos de manufatura. Outro exemplo notável é o da Dell, que revolucionou a indústria de computadores com um novo conceito de administração da cadeia de fornecimento.

$\mathrm{Na}$ relação com os mercados, dado o grande volume de consumidores, por mais que as empresas tentem identificar seus traços e segmentá-los, a relação é altamente impessoal. Além disso, essas empresas têm conhecimento de que a diversidade precisa ser controlada para não prejudicar a eficiência. Assim, a famosa frase de Ford ("O cliente pode ter um carro de qualquer cor, desde que seja preta") continua tendo certo sentido. Portanto, o papel das Vendas e Marketing é "convencer os clientes e adaptá-los ao modo operacionalmente excelente de a empresa fazer negócios" (Treacy \& Wieserma, 1995).

\subsubsection{Inovação em Produto}

As companhias que competem com uma estratégia de Inovação em Produto estão continuamente investindo para criar conceitos de produto radicalmente novos para clientes e segmentos de mercado definidos. A função crítica é Pesquisa \& Desenvolvimento \& Engenharia (P\&D\&E).

Exemplos de indústrias nas quais a competitividade é regulada pela Inovação em Produto são as indústrias de Tecnologia da Informação (TI), Telecomunicações, Computação e Internet. O mesmo padrão é encontrado na indústria Biomédica (Ciências da Vida). Porém, há inovadores no mercado de consumo, como a Sony e a $3 \mathrm{M}$.

Tais empresas garantem seu sucesso econômico com a alta lucratividade que alcançam no período em que usufruem a posição de monopólio de mercado. O que é crítico para esse tipo de companhia é a rápida concepção de novos produtos e de seus respectivos processos de produção, que evoluem de escala laboratorial para escala industrial.

A função Vendas/Marketing apresenta características diferentes em relação ao caso anterior, uma vez que, em geral, a empresa precisa "negociar" o lançamento de novos produtos no mercado com clientes potenciais antes que investimentos mais substanciais sejam feitos. Isto implica identificar os clientes mais propensos à inovação e discutir com eles as vantagens da adoção de produtos inovadores.

\subsubsection{Orientada para Cliente}

As empresas que adotam a estratégia Orientada para Cliente são voltadas para as necessidades de clientes específicos e procuram se especializar no desenvolvimento de produtos, sistemas e soluções que atendam a suas demandas atuais e futuras. Para isso, tais companhias priorizam o desenvolvimento do conhecimento sobre cada cliente e seu negócio: Vendas \& Marketing torna-se a função crítica, impulsionando os esforços de Pesquisa, Desenvolvimento e Engenharia, e também de Operações.

A IBM era considerada o exemplo dessa estratégia (Wheelwright \& Hayes, 1985). A Caterpillar é considerada como um caso de "intimidade com o cliente" (Treacy \& Wieserma, 1995).

A indústria de embalagens representa um caso interessante. Apesar de as embalagens ganharem cada vez mais importância no sucesso de um produto, os produtores finais, em geral, não estão interessados em montar infra-estrutura própria ou desenvolver competências dentro da própria empresa para a produção de embalagens. Portanto, o relacionamento com uma empresa de embalagens envolve mais que a entrega de um produto. A orientação estratégica das empresas de embalagem implica a identificação e o desenvolvimento de soluções específicas e sistemas de embalagem que maximizem o valor do produto final, alavancando a competitividade da empresa cliente em função das expectativas de mercado.

$\mathrm{O}$ forte relacionamento com os clientes (Intimidade com o Cliente, segundo Treacy \& Wiersema, 1995), sobre os quais a função Vendas é responsável, orienta Pesquisa \& Desenvolvimento \& Engenharia e Operações no desenvolvimento de soluções específicas em um modo pró-ativo. Em casos como esses, Operações precisa dar respostas e ser flexível às 
necessidades dos clientes, e não necessariamente atender a padrões de classe mundial. Precisa ser flexível para atender às demandas dos clientes da melhor maneira possível. É por esta razão que empresas que adotam a estratégia Orientada para Cliente estabelecem in-house plants ou assumem atividades relativas ao estoque dos clientes. O sistema de Operações tem de ser ágil, não necessariamente enxuto.

\subsection{Alinhando a estratégia competitiva à gestão de competências}

Consideramos assim que no processo de criação de vantagens competitivas é necessário alinhar a estratégia competitiva e a competência essencial.

À escolha de uma estratégia se associa uma competência na qual a empresa precisa ser "mais excelente que seus competidores"; as outras duas competências devem sustentar a primeira. A Tabela 1 sintetiza esta tipologia de estratégias e competências.

Em suma, uma empresa, para ser competitiva, precisa realmente compreender como se articulam competência essencial e estratégia empresarial.

\section{As redes interorganizacionais}

O modelo Competências-AprendizagemEstratégia, apresentado anteriormente para o caso de empresas consideradas isoladamente, sofre mudanças quando se trata de redes interorganizacionais. Ou seja, na medida em que há busca de eficiência coletiva por intermédio de sistemas de empresas, a questão da formação de competências e da escolha de estratégias assume características específicas.

Embora seja fenômeno recente, as redes interempresariais já dispõem de considerável corpo de conhecimento. Diversos aspectos mereceram discussão, como, por exemplo, os determinantes para uma organização vir a estabelecer uma rede (Oliver, 1990), o impacto da estrutura de uma rede na capacidade de inovação de uma firma (Ahuja, 2000), a influência das relações de uma organização em sua capacidade de formar novas alianças (Gulati, 1999), as peculiaridades de redes de PMEs (Human \& Provan, 1997) e a centralidade da colaboração entre empresas para a inovação em setores de rápido desenvolvimento tecnológico (Powell et al., 1996).

Tabela 1 - Tipos de estratégia e competências essenciais.

\begin{tabular}{|c|c|c|c|}
\hline \multirow{2}{*}{$\begin{array}{l}\text { Estratégia } \\
\text { competitiva }\end{array}$} & \multicolumn{3}{|c|}{ Função } \\
\hline & Operações & $\begin{array}{c}\text { Desenvolvimento de } \\
\text { produto }\end{array}$ & Vendas/Marketing \\
\hline $\begin{array}{l}\text { Excelência } \\
\text { Operacional }\end{array}$ & $\frac{\frac{\text { Manufatura classe }}{\text { mundial/produção }}}{\underline{\text { enxuta }}}$ & Inovações incrementais & $\begin{array}{c}\text { Convencer o mercado de que a relação } \\
\text { qualidade/preço dos produtos/serviços } \\
\text { oferecidos é ótima }\end{array}$ \\
\hline $\begin{array}{l}\text { Inovação em } \\
\text { Produto }\end{array}$ & $\begin{array}{l}\text { Scale up e } \\
\text { produção primária }\end{array}$ & $\frac{\text { Inovações radicais }}{\underline{\text { breakthrough })}}$ & $\begin{array}{l}\text { Preparar o mercado e educar os clientes } \\
\text { potenciais para a adoção da inovação }\end{array}$ \\
\hline $\begin{array}{l}\text { Orientada para } \\
\text { Cliente }\end{array}$ & Manufatura ágil & $\begin{array}{l}\text { Desenvolvimento de } \\
\text { sistemas } \\
\text { (produtos/serviços) } \\
\text { específicos }\end{array}$ & $\frac{\text { Desenvolver relações com clientes }}{\text { específicos para compreender }}$ \\
\hline
\end{tabular}

Observação: foram sublinhadas as competências essenciais para cada estratégia. 
Esses estudos, assim como outros sobre o assunto, discutem principalmente aspectos de redes interempresariais, nas quais há relações horizontais. Porém, no que diz respeito especificamente a redes (ou cadeias) de suprimentos, em que a relação é essencialmente vertical, os estudos são principalmente descritivos e focalizados nas grandes corporações (Harland et al., 2001).

No caso de relações horizontais, as empresas têm relações simétricas, recíprocas; duas companhias formam uma aliança de negócios (business alliance), ou mesmo criam uma aliança estratégica, porque têm recursos, especialmente competências, complementares e a associação visa a criar sinergias que alavanquem o potencial competitivo de ambas.

Para o estudo de redes de relações verticais há diferentes enfoques. No campo da Gestão de Operações, a abordagem é do tipo Gestão da Cadeia de Suprimentos, inspirado inicialmente pelo modelo japonês de gestão e na estrutura do keiretsu desenvolvido na indústria japonesa (Fruin, 1993). Seguindo essa tendência, “(...) a literatura de Gestão de Operações tem se concentrado principalmente nas relações genéricas de cooperação entre cliente e fornecedor em duas áreas específicas: cooperação em Operações (logística, planejamento da produção, controle e qualidade) e co-design" (Spina \& Zotteri, 2001).

O segundo enfoque “(...) foi construído a partir da Teoria da Organização Industrial e da Nova Economia Institucional, na vertente representada pela Teoria dos Custos de Transação" (Farina, 1999). Segundo essa autora, o conceito nuclear se deve a Coase, que introduziu a idéia da "firma como um nexo de contratos". Assim, "a microteoria das instituições, que trata das estruturas de governança e da anatomia das organizações, foi desenvolvida para compreender a firma e contratos específicos, enquanto a macroteoria lida com o ambiente institucional geral (...). Governar a transação significa incentivar o comportamento desejado e, ao mesmo tempo, monitorá-lo. Essa governança pode ser obtida por meio de sistema de preços [ou] pode exigir a elaboração de contratos em que sejam predefinidos instrumentos de incentivo e controle, tais como multas, auditorias ou prêmios por resultados" (Farina, 1999). Portanto, a formação das cadeias de suprimentos seria uma escolha racional e objetiva dos vários participantes do processo de produção. É importante para tal escolha uma análise dos diferentes aspectos do relacionamento e os tradeoffs entre eles (Spina \& Zotteri, 2001).

Um terceiro enfoque joga luz sobre as relações de comando e poder na cadeia. Essa dimensão é particularmente elaborada pelos estudos desenvolvidos por Gereffi (1994) a respeito da formação de cadeias de commodities globais. Por exemplo, em seus estudos nas indústrias de vestuário e calçados, mostrou como o comando da cadeia concentra-se nas grandes empresas de distribuição e naquelas que detêm as griffes. Essa questão torna-se crucial para compreender quais empresas podem governar a cadeia, estabelecer as regras e procedimentos para a sua operação conjunta, e assumir o comando das atividades mais lucrativas.

Harland et al. (2001), comentando texto anterior de Grandori \& Soda, assumem a distinção entre redes entre pares (parity based) e redes centralizadas, destacando que "isso tem clara relevância em termos do modo pelo qual as companhias focais podem gerenciar suas redes de fornecimento dependendo de seu poder relativo". No modelo por eles proposto, o conceito de poder é operacionalizado por intermédio de uma variável denominada influência.

Para se tornarem membros de arranjos interorganizacionais, as firmas devem negociar seus recursos: infra-estrutura, bens intangíveis e competências organizacionais. A questão básica de pesquisa seria, então: a posição relativa de determinada empresa na rede interorganizacional líder ou seguidora, relações de paridade ou de subordinação -; seria uma função da importância relativa de sua competência distintiva para o 
desempenho de toda a rede. Isso implicaria a distribuição e complementaridade de competências entre as empresas participantes de determinado arranjo interorganizacional. Evidentemente, haveria também impactos em termos das escolhas estratégicas das empresas.

\section{Pesquisa de campo: aspectos metodológicos}

Na construção de nosso modelo, primeiramente consideramos que, quando uma empresa decide autonomamente sobre sua estratégia competitiva, há três escolhas ótimas: Excelência Operacional, Inovação em Produto e Orientada para Cliente. A hierarquização das competências e sua gestão deveria, então, seguir o que foi proposto na Tabela 1 .

Depois, vimos que a inserção em uma rede interorganizacional influencia a escolha da estratégia e a formação de competências. Em outras palavras, a escolha da estratégia é condicionada pela posição da empresa na rede; ao mesmo tempo, esse posicionamento é função da importância relativa das competências que a empresa aporta para o desempenho competitivo de toda a rede.

Esse modelo foi então aplicado para a realização de diagnóstico abrangente da indústria brasileira, vivendo intenso processo de internacionalização. Isso condicionou as opções metodológicas em termos de definição do universo e da amostra.

O universo escolhido para a aplicação do modelo foi aquele das empresas certificadas pela família de normas NBR ISO 9000. Essas empresas, motivadas em atender aos padrões de qualidade estabelecidos internacionalmente, realizaram as mudanças necessárias para estabelecer procedimentos de gestão que atendessem aos quesitos para certificação. Partimos assim da hipótese de que o universo de companhias com certificado ISO 9000 é um grupo de elite que já realizou as mudanças mais imediatas para atender às pressões pela competitividade internacional.

No Brasil, o universo das companhias industriais que possuem certificação de acordo com as normas ISO 9001 e 9002 é constituído de aproximadamente 1.600 empresas. Em 1999, foram enviados 1.516 questionários para diretores industriais dessas companhias. Foram respondidos 490, e destes 470 foram considerados válidos para os fins deste estudo.

Os principais tópicos do questionário foram:

a) Características gerais da empresa.

b) Fatores determinantes de mercado para a formulação estratégica.

c) Função crítica de sucesso.

d) Posição da empresa no ciclo de vida do produto.

e) Relacionamentos a montante, a jusante e lateralmente.

f) As competências desenvolvidas pela empresa tendo em vista as diferentes fases do ciclo de vida do produto.

g) Investimentos em treinamentos e educação de Recursos Humanos.

A Tabela 2 demonstra que a amostra é razoavelmente representativa do segmento de empresas industriais brasileiras que está se integrando ao desafio de uma economia globalizada, pois:

- inclui não só o grupo das maiores empresas brasileiras (nacionais e subsidiárias), mas também parcela significativa de pequenas e médias empresas;

- apresenta distribuição em termos de origem e controle do capital que reflete a realidade brasileira no momento em que foi realizada a pesquisa.

As empresas selecionadas para o estudo operavam nos seguintes mercados: Automotivo, Químico, Eletrônico, Máquinas e Equipamentos, Borrachas e Plásticos, Siderurgia e Metalurgia. 


\section{Análise de dados e resultados}

O primeiro aspecto abordado no questionário procurava identificar a estratégia competitiva da empresa pesquisada. Para isso foi adotado o esquema proposto por Bolwijn \& Kumpe (1990), perguntando: Quais seriam as características de mercado mais importantes a serem consideradas na definição da estratégia competitiva? As respostas coletadas são apresentadas na Tabela 3.

A análise da tabela revela que os três fatores mais importantes para essas empresas competirem nos mercados são: preço, qualidade e entrega, configurando a estratégia de Excelência Operacional.
Por outro lado, também foi solicitado que as empresas classificassem quais seriam as funções organizacionais mais importantes para o alcance de seus objetivos. Cinco funções foram apresentadas: Manufatura, Logística, Pesquisa \& Desenvolvimento \& Engenharia e Vendas/Marketing. As respostas são apresentadas na Tabela 4.

É importante mencionar que essa foi a única unanimidade encontrada no processamento dos dados: para as companhias da amostra, independente de tamanho ou origem, a função Vendas/ Marketing sempre foi considerada a mais importante para o cumprimento da estratégia competitiva. A segunda função mais importante foi Produção.

Tabela 2 - Distribuição da amostra em termos de tamanho e origem do capital.

\begin{tabular}{lccccc}
\hline & $\begin{array}{c}\text { Pequenas } \\
(\mathbf{n}<\mathbf{9 9})\end{array}$ & $\begin{array}{c}\text { Médias } \\
(\mathbf{1 0 0}<\mathbf{n}<\mathbf{4 9 9})\end{array}$ & $\begin{array}{c}\text { Grandes } \\
(\mathbf{5 0 0}<\mathbf{n}<\mathbf{9 9 9})\end{array}$ & $\begin{array}{c}\text { Muito grandes } \\
(\mathbf{n}>\mathbf{1 0 0 0})\end{array}$ & Total \\
\hline $\begin{array}{c}\text { Empresa } \\
\text { nacional* }\end{array}$ & $23,8 \%$ & $30,2 \%$ & $6,4 \%$ & $9,8 \%$ & $70,2 \%$ \\
$\begin{array}{c}\text { Empresa } \\
\text { subsidiária }\end{array}$ & $2,5 \%$ & $14,0 \%$ & $6,4 \%$ & $6,8 \%$ & $29,8 \%$ \\
\hline $\begin{array}{l}\mathrm{n}=\text { número de empregados. } \\
\text { *Empresa nacional: empresa com capital majoritariamente brasileiro. }\end{array}$ &
\end{tabular}

Tabela 3 - Fator mais importante para a empresa competir no mercado.*

\begin{tabular}{lccccc}
\hline & Preço & Qualidade & Entrega & Inovação & Diversidade \\
\hline Indicadores de & \multicolumn{2}{c}{ Excelência Operacional } & Produto & Relação com o cliente \\
Média amostral & 4,69 & 4,68 & 4,41 & 3,77 & 3,52 \\
\hline
\end{tabular}

*As respostas foram dadas em uma escala de 1 a 5 .

Tabela 4 - Funções críticas para realização dos objetivos estratégicos.

\begin{tabular}{ccccc}
\hline & Manufatura & Logística & P\&D\&E & $\begin{array}{c}\text { Vendas e } \\
\text { Marketing }\end{array}$ \\
\hline $\begin{array}{c}\text { Competência } \\
\text { essencial } \\
\begin{array}{c}\text { Média } \\
\text { amostral }\end{array}\end{array}$ & \multicolumn{2}{c}{ Operações } & Desenvolvimento de produto & $\begin{array}{c}\text { Vendas e } \\
\text { Marketing }\end{array}$ \\
\hline
\end{tabular}


Com isto, se considerarmos a relação entre estratégia e competência essencial, como apresentado na Tabela 1 , notaremos certo "desalinhamento": apesar de a maioria das empresas declarar estar competindo com estratégia de Excelência Operacional, a função (e a competência) mais importante seria Vendas/ Marketing. Uma possível explicação para essa resposta seria o efeito da participação em redes interorganizacionais sobre a formação de competências e sobre o campo de escolhas estratégicas das empresas.

No questionário solicitamos aos respondentes que considerassem duas fases no Ciclo de Vida do Produto: a fase de inovação e desenvolvimento e a fase de manufatura e operações. $\mathrm{Na}$ primeira fase solicitamos que considerassem três atividades: A. P\&D e scaling up (P\&D\&E); B. Projeto de Processo e Produto; e C. Adaptação de Processo e Produto. Na segunda pedimos que considerassem: D. Gestão da Qualidade; E. Gestão da Cadeia de Fornecimento; e F. Logística (gestão dos fluxos físicos e de informações).

Solicitou-se, então, que se identificassem os responsáveis pela execução de tais atividades. Foram apresentadas as seguintes alternativas: somente a empresa (auto-suficiência), a empresa e o(s) cliente(s) (casos de co-design ou cooperação em Operações), a empresa e a matriz ou somente a matriz (no caso das subsidiárias), a firma e o licenciador (casos de transferência de tecnologia) ou ainda apenas os clientes (casos de subcontratação pura). Mesmo nas atividades não desenvolvidas pela própria empresa, os respondentes marcaram quem estaria com a responsabilidade.

$\mathrm{Na}$ análise, consideramos primeiramente se cada uma das empresas declarava manter ou não alguma relação com outras empresas para o desempenho de pelo menos uma dessas atividades. Com isso, foi possível classificar as empresas que operavam em total isolamento e aquelas que estavam de alguma forma conectadas a outras. Cerca de $30 \%$ das empresas brasileiras declararam atuar de forma isolada. Somente uma das subsidiárias declarou que operava independentemente da matriz e que não estava ligada a nenhuma empresa local.

Para as empresas que participavam de algum tipo de rede, analisamos as respostas de acordo com o perfil de suas atividades e assumimos que a empresa possuía as competências na área em que ela declarava exercer alguma atividade. Dependendo do conjunto de competências que cada empresa podia desenvolver, criamos categorias para caracterizar sua posição relativa na rede interempresarial, como mostra a Tabela 5.

Tabela 5 - Categorização das empresas de acordo com as competências informadas.

\begin{tabular}{ccccc}
\hline $\begin{array}{c}\text { Atividades desenvolvidas na } \\
\text { empresa como indicadores de } \\
\text { competências organizacionais }\end{array}$ & \multicolumn{2}{c}{ Empresas participantes de redes } & Empresas isoladas \\
\hline P\&D\&E & Sim & Não & Não & \\
$\begin{array}{c}\text { Desenvolvimento de produto- } \\
\text { processo }\end{array}$ & Sim & Sim & Não & $\begin{array}{c}\text { Estes casos não foram } \\
\text { analisados }\end{array}$ \\
$\begin{array}{c}\text { Adaptação de produto-processo } \\
\text { Operações }\end{array}$ & Sim & Sim & Sim & \\
Posição mais provável & $\begin{array}{c}\text { Líder ou } \\
\text { aliança de } \\
\text { negócios }\end{array}$ & $\begin{array}{c}\text { Primeiro } \\
\text { nível }\end{array}$ & $\begin{array}{c}\text { Segundo } \\
\text { nível }\end{array}$ & Empresas isoladas \\
& & & & \\
\hline
\end{tabular}


Finalmente, analisamos os dados em termos dos setores industriais nos quais operam as empresas. Os resultados são apresentados na Tabela 6.

O primeiro resultado é uma visão panorâmica dos tipos de redes interorganizacionais que estão sendo estabelecidos. De certa maneira, pode-se considerar um retrato grosseiro da nova arquitetura da indústria no Brasil.

$\mathrm{O}$ segundo ponto se refere à posição relativa das empresas nessas redes. De acordo com o apresentado na Tabela 7, há certa desproporção em termos de "quem está no comando?": claramente, há muito mais empresas estrangeiras em posições de liderança do que nacionais. Mas, para chegar a conclusões mais esclarecedoras a esse respeito, as informações dessa tabela devem ser combinadas com as da Tabela 6 .

A Tabela 6 apresenta o tipo de arranjo que é predominante em distintos tipos de indústrias. Inicialmente, constatamos que a grande maioria das empresas nacionais ou faz parte de redes de fornecimento nas quais o relacionamento é vertical, assimétrico e hierárquico, ou então são empresas isoladas, competindo apenas com seus recursos próprios. Ou seja, a maior parte das empresas nacionais ocupa posições de menor importância ou influência na estratégia e no desempenho da rede a que pertence. Isto sinalizaria que provavelmente essas empresas não chegaram a acumular competências que permitissem negociar melhor colocação nas redes.

\section{Tabela 6 - Posicionamento das empresas pesquisadas em diferentes arranjos empresariais.}

\begin{tabular}{|c|c|c|c|c|c|}
\hline \multirow{6}{*}{$\begin{array}{l}\text { Indústria } \\
\text { no Brasil }\end{array}$} & Tipo de rede & Proporção & Setor industrial & \multicolumn{2}{|c|}{ Características das empresas } \\
\hline & Aliança & $4,8 \%$ & $\begin{array}{l}\text { Químico } \\
\text { Máquinas } \\
\text { Eletrônicos }\end{array}$ & \multicolumn{2}{|c|}{$\begin{array}{l}\text { Principalmente empresas muito grandes } \\
\text { Nacionais > Subsidiárias }\end{array}$} \\
\hline & \multirow{3}{*}{$\begin{array}{c}\text { Rede de } \\
\text { fornecimento }\end{array}$} & \multirow{3}{*}{$73,4 \%$} & \multirow{3}{*}{$\begin{array}{l}\text { Automotivo } \\
\text { Borracha e plástico } \\
\text { Metais e aço }\end{array}$} & Líder & $\begin{array}{l}\text { Grandes e muito grandes } \\
\text { Subsidiárias > Nacionais }\end{array}$ \\
\hline & & & & 1º nível & $\begin{array}{l}\text { Médias e grandes } \\
\text { Subsidiárias = Nacionais }\end{array}$ \\
\hline & & & & $2^{\underline{o}}$ nível & $\begin{array}{c}\text { Pequenas e médias } \\
\text { Nacionais } \gg \text { Subsidiárias }\end{array}$ \\
\hline & Isoladas & $21,8 \%$ & $\begin{array}{c}\text { Todas } \\
\text { Maior participação: } \\
\text { máquinas } \\
\text { Menor: automotivo }\end{array}$ & & $\begin{array}{l}\text { Todos os tamanhos } \\
\text { osidiárias = Nacionais }\end{array}$ \\
\hline
\end{tabular}

Tabela 7 - Posição mais provável das empresas de acordo com sua origem.

\begin{tabular}{lcccc}
\hline $\begin{array}{c}\text { Posição provável no } \\
\text { arranjo }\end{array}$ & $\begin{array}{c}\text { Líder de rede ou } \\
\text { aliança }\end{array}$ & $\begin{array}{c}\text { Primeiro } \\
\text { nível }\end{array}$ & $\begin{array}{c}\text { Segundo } \\
\text { nível }\end{array}$ & $\begin{array}{c}\text { Empresas } \\
\text { isoladas }\end{array}$ \\
\hline Subsidiárias & $60,0 \%$ & $33,0 \%$ & $6,0 \%$ & $1,0 \%$ \\
Empresas nacionais & $4,5 \%$ & $20,5 \%$ & $45,7 \%$ & $29,3 \%$ \\
\hline
\end{tabular}


Observamos também que as empresas nacionais que criaram relações horizontais por intermédio de alianças estratégicas estão concentradas em três áreas: Química, Equipamentos/ Máquinas e Eletrônica. Este resultado seria indicativo de que, mesmo em campos de maior intensidade tecnológica, se o país tem empresas com competências internacionalmente reconhecidas, há a possibilidade de buscar relações nas quais haja intercâmbio com ganhos para ambas as partes.

A amostra incluía grandes empresas nacionais pertencentes às indústrias siderúrgica e metalúrgica. Entretanto, as informações obtidas caracterizam suas posições como de fornecedoras em cadeias de suprimento. Podemos aventar a idéia de que, pelo fato de ocuparem posições a montante nas cadeias produtivas, elas enfrentam dificuldades para exercer influência sobre as demais participantes das redes.

Já a maioria das empresas de Borracha, Plástico e de Metalurgia participantes da amostra são parte das cadeias de suprimento dos setores Químico, Eletrônico e Automotivo. Esse tipo de empresa geralmente concentra suas competências na área de Operações e opera de acordo com padrões locais - baixo custo -, o que não necessariamente é sinal de Excelência Operacional (Fleury, 1995). O fato de que a maioria dessas empresas identificou Vendas/Marketing como função mais importante pode ser um indicador de que a empresa ocupa posição de venda de serviços de manufatura: para produzir precisa "vender" as competências e os recursos relativos a Operações para os demais participantes da rede.

É interessante observar que a presença inesperada, porém significativa, de pequenas e médias subsidiárias é mais uma indicação de deslocamento de empresas nacionais que não oferecem as competências requeridas pelas líderes.

Finalmente, temos as empresas isoladas que não são capazes de participar das redes. Elas se concentram em produção de maquinaria, suprindo provavelmente mercados locais com modelos específicos.

Em síntese, parece lícito concluir que o número de empresas nacionais capazes de ocupar posições de liderança em redes interorganizacionais internacionais é limitado e concentrado em alguns nichos. A admissão de tal situação é crucial para, entre outros fins, compreender melhor a competitividade do país e para a criação de subsídios para eventual proposição de política industrial.

\section{Comentários finais}

O objetivo deste estudo foi analisar as consequências da formação de redes interorganizacionais internacionais, que são pré-requisito para a consecução de metas de eficiência coletiva. Para isso, criamos um referencial conceitual no qual questões que são tradicionalmente analisadas a partir de abordagens de Organização Industrial poderiam ser tratadas pelo uso de conceitos e modelos de Gestão de Operações.

Utilizando esse referencial, as questões de pesquisa podem ser respondidas como se segue. $\mathrm{Na}$ formação de redes interorganizacionais, a posição a que uma empresa pode aspirar depende das competências que ela acumulou e da importância relativa dessas competências para o desempenho da rede como um todo.

Num nível mais agregado, a aplicação do modelo traz evidências que auxiliam na avaliação do potencial do país para se tornar membro ativo de redes internacionais. Assim, podemos identificar as questões de governance e as conseqüências, em termos de tomada de decisão, nos planos da empresa, das regiões e do país. Dependendo da posição relativa que as empresas de determinado país ocupam nas redes, pode haver questões de vulnerabilidade a serem consideradas e possíveis investimentos para incrementar a competitividade podem ser desprovidos de sustentação a médio e longo prazos. 
Por último, é importante salientar que no cenário atual de economia globalizada, de reconfiguração das empresas globais na busca da eficiência coletiva, procurar compreender a dinâmica do processo de reestruturação do tecido industrial de um país como o Brasil é como tentar montar um quebra-cabeça caleidoscópico: cada vez que uma figura se forma, uma das peças se mexe, alterando a figura desenhada. A contribuição deste texto é tentar fornecer alguns conceitos teóricos e evidências empíricas que ajudem a melhor compreender esse caleidoscópio.

\section{Referências Bibliográficas}

AHUJA, G. Collaboration networks, structural holes and innovation: a longitudinal study. Administrative Science Quarterly, v. 45, p. 425455, 2000.

AKKERMANS, H.; BOGERD, P.; VOS, B. Virtuous and vicious cycles on the road towards international supply chain management. International Journal of Operations and Production Management, v. 19, n. 5/6, p. 565-581, 1999.

BARTLETT, C.; GHOSHAL, S. Managing across borders. Boston: Harvard Business School Press.

BOLWIJN, P. T.; KUMPE, T. Manufacturing in the 1990s: productivity, flexibility and innovation. Long Range Planning, v. 23, n. 4, p. 44-57, 1990.

COLE, R. Strategies for learning. Berkeley: University of California Press, 1989.

D’AVENI, R. Hipercompetição. Rio de Janeiro: Campus, 1995.

DAY, G. S.; REIBSTEIN, D. J. Dynamic competitive advantage. Wiley, 1998.

DOSI, G.; CORIAT, B. The nature and accumulation of organizational competences/capabilities. Revista Brasileira de Inovação, v. 1, n. 2, jul./dez. 2002.

FARINA, E. M. Competitividade e coordenação de sistemas agroindustriais: um ensaio conceitual. Gestão \& Produção, v. 6, n. 3, p. 147-161, 1999.

FLAHERTY, M. T. Global operations management. McGraw-Hill Books, 1996.

FLEURY, A. Quality and productivity in the competitive strategies of Brazilian industrial enterprises. World Development, v. 23, n. 1, 1995.

FRUIN, W. The Japanese enterprise system: competitive strategies and cooperative structures. New York: Oxford University Press, 1993.
GEREFFI, G. Capitalism, development and global commodity chains. In: SKLAIR, L. (Ed.). Capitalism and development. London: Routledge, 1994.

GILGEOUS, V.; PARVEEN, K. Core competency requirements for manufacturing effectiveness. Integrated Manufacturing Systems, v. 12, n. 3, p. 217-227, 2001.

GULATI, R. Network location and learning: the influence of network resources and firm capabilities on alliance formation. Strategic Management Journal, v. 20, p. 397-420, 1999.

HARLAND, C. M.; LAMMING, R. C.; ZHENG, J.; JOHNSEN, T. E. A taxonomy of supply networks. The Journal of Supply Chain Management, p. 2127, Fall 2001.

HAYES, R.; UPTON, D. Operations based strategy. California Management Review, v. 40, n. 4, p. 825, 1998.

HUMAN, S.; PROVAN, K. An emergent theory of structure and outcomes in small-firm strategic manufacturing networks. Academy of Management Journal, v. 40, n. 2, 1997.

KROGH, G.; ROOS, J. A perspective on knowledge, competence and strategy. Personnel Review, v. 24, n. 3, p. 56-76, 1995.

MIYAKE, D. I. The JIT, TQC and TPM paradigms: contributions for planning integrated applications in manufacturing firms. 1995. 192p. Dissertation $(\mathrm{PhD})$ - Tokyo Institute of Technology, Tokyo.

MOTWANI, J.; YOUSSEF, M.; KATHAWALA, Y.; FUTCH, E. Supplier selection in developing countries: a model development. Integrated Manufacturing Systems, v. 10, n. 3/4, p. 154-161, 1999. 
OLIVER, C. Determinants of interoganizational relationships: integration and future directions. The Academy of Management Review, v. 15, n. 2, p. 241-265.

PORTER, M. Competitive strategy: techniques for analizing industries and competitors. New York: The Free Press, 1980.

PORTER, M. What is strategy? Harvard Business Review, v. 74, n. 6, p. 61-78, 1996.

POWELL, K.; KOPUT, K.; SMITH-DOERR, L. Interorganizational collaboration and the locus of innovation: networks of learning in biotechnology. Administrative Science Quarterly, v. 41, n. 1, 1996.

PRAHALAD, C. K.; HAMEL, G. The core competence of the corporation. Harvard Business Review, v. 68, n. 3, p. 79-91, 1990.

PRAHALAD, C. K.; LIEBERTHAL, K. The end of corporate imperialism. Harvard Business Review, Jul./Aug. 1998.

PROENÇA, A. Dinâmica estratégica sob uma perspectiva analítica: refinando o entendimento gerencial. Rio de Janeiro: Universidade Cândido Mendes, ARCHÉ, 1999. ano VIII, n. 23.
SHI, Y.; GREGORY, M. International manufacturing networks-to develop global competitive capabilities. Journal of Operations Management, v. 16, p. 195-214, 1998.

SPINA, G.; ZOTTERI, G. The strategic context of customer-supplier relationships: evidence from a global survey. Integrated Manufacturing Systems, v. 12, n. 7, p. 483-492, 2001.

TIDD, J.; BESSANT, J.; PAVITT, K. Integrating technological, market and organizational change. New York: Wiley, 1998.

TREACY, M.; WIERSEMA, F. The discipline of market leaders. Addison Wesley, 1995.

WHEELWRIGHT, S.; HAYES, R. Competing through manufacturing. Harvard Business Review, p. 99-109, Jan./Feb. 1985.

WOODWARD, J. Industrial organization: theory and practice. London: Tavistock Publications, 1965.

\section{COMPETITIVE STRATEGIES AND CORE COMPETENCIES: PERSPECTIVES FOR THE INTERNATIONALIZATION OF INDUSTRY IN BRAZIL}

Abstract

One of the key features of the new economy is the change from individual to collective efficiency. The main determinant of the successful delivery of the goods and services demanded by global or regional markets is the joint performance of firms networked as strategic alliances, production or value chains or industrial clusters. The starting point for the development of this study was the idea that participation in an entrepreneurial network influences the conditions for the establishment of the firms' strategies and the formation of competencies. Searching for empirical evidences for that argument, we developed a survey (490 respondents) about the recent evolution of industry in Brazil to see how local firms are redefining their strategies, organization and building relationships to survive and compete in a globalised and networked economy. The outcomes of the research reinforce the importance of networks as a basic concept for the analysis of competitiveness at firm and aggregate levels. Regarding the new organizational architecture of the Brazilian industry, what was observed was the widespread alignment of local firms into value chains led by TNC's and their subsidiaries, a limited number of strategic alliances, and a significant number of isolated firms, unable to respond to the demands of the new competition.

Key words: international manufacturing, supply chains, interorganizational networks, brazilian industry. 